\title{
Commentary
}

\section{Revamped vaccination policy in India, need of the hour}

\author{
Swayam Pragyan Parida1, Vikas Bhatia ${ }^{2}$, G. Alekhya ${ }^{1 *}$ \\ ${ }^{1}$ Department of Community Medicine and Family Medicine, AIIMS Bhubaneswar, Odisha, India \\ ${ }^{2}$ AIIMS Bibinagar, Hyderabad, Telangana, India
}

Received: 11 August 2021

Revised: 09 September 2021

Accepted: 08 October 2021

\section{*Correspondence:}

Dr. G. Alekhya,

E-mail: alekhyagajjala17@gmail.com

Copyright: () the author(s), publisher and licensee Medip Academy. This is an open-access article distributed under the terms of the Creative Commons Attribution Non-Commercial License, which permits unrestricted non-commercial use, distribution, and reproduction in any medium, provided the original work is properly cited.

\begin{abstract}
The unprecedented COVID pandemic has caused catastrophic loss all over the world. India has faced a flabbergasting second COVID wave. The current COVID mutant strain is more virulent and has become a variant of concern (VOC) with its high infectivity rate. The current second wave is more detrimental when compared to the first wave, where its transmissibility is high, affecting the younger generation, and even the mortality rate is high. Currently, there is no specific treatment against COVID-19. The health care workers (HCW's) have been fighting the pandemic tirelessly since the beginning of the pandemic, and many were affected, and severe loss of HCWs occurred. The only ray of hope in fighting against this deadly virus is vaccination. Studies have shown that COVID vaccination is effective in preventing the severity of the disease. Hence vaccination is now is the need of the hour. COVID vaccination has to be taken rampant with vaccinating every citizen of the country in the current crisis. The government of India should make serious efforts that vaccination is available and accessible to everyone. With every citizen being vaccinated, one can flatten the current wave and also can prevent further outbreaks.
\end{abstract}

Keywords: COVID second wave, COVID vaccination, HCW's

\section{INTRODUCTION}

The COVID-19 pandemic is already in its second phase, and India is reporting around 0.3 million COVID-19 positive patients. ${ }^{1}$ The peculiarity of this phase is that more morbidity and mortality is observed in the younger generation, development of mutants, etc. The second wave is speculated to rise further till the end of May 2021 in view of many emerging mutants/VOC. Out of many variants, B.I.67.1 has been considered as the variant of global concern owing to the spread in more than 44 countries. Presently it has posed to become the major dominant strain in the UK. ${ }^{2}$ Another aspect seen in India is the higher infection rate among rural people.

During this global crisis, HCWs are at a greater risk of infection as they deal with COVID-19 patients directly or indirectly through the infectious materials generated while treating patients. ${ }^{3}$ As per the centre for disease control and prevention (CDC) morbidity and mortality report in April 2020, HCW's constitute 3\% of COVID-19 cases in the USA. It has been of great concern that HCW status was only reported in $16 \%$ of cases. In states which provided infection reports, it has been seen that HCWs constitute almost $11 \%$ of cases.

In India, around 270 doctors have died in the second wave of COVID-19, and it is estimated that 50 doctors have died in a single day, as per a report released by the Indian medical association. ${ }^{4}$ The demise of learned manpower is a huge loss to the country. This loss is undoubtedly increasing an environment of fear among HCWs at the workplace. Beyond the workplace, the HCWs are worried about the health of their family 
members, too, as secondary transmission from them to family members and the community is there. ${ }^{5}$ Elderly family members are at a significant threat of contracting an infection from HCWs. Currently, there is a paucity of data on the COVID-19 infection rate among the family members of HCWs.

\section{CHALLENGES FACED BY INDIA}

Vaccine shortage leaving behind millions of people facing the threat of COVID-19 infection. ${ }^{6}$ Shortage of beds, ICU facility, oxygen, PPEs are leading to enhanced mortality. ${ }^{7}$ More rural people are getting an infection because of lack of testing facilities, unawareness among people, and more cohesiveness among rural societies of India. ${ }^{8}$ Lack of trained manpower and poor infrastructure in rural areas. PHCs are not equipped to take the massive burden of COVID-19 patients. The primary health care system is not geared up to face this challenge. Mutants are becoming the dominant strain with higher transmissibility and with the ability to evade the immune mechanism. ${ }^{9}$ The younger generation is acquiring the infection at a higher rate. The speculation expressed by the reputed medical societies of India is that the third wave might come up in September to October 2021 with a potential threat to children. ${ }^{10}$ Increasing mental health crisis and fatigue among HCW's. ${ }^{11}$

\section{VACCINATION POLICY}

As there is no specific treatment available for COVID-19, preventive measures like COVID appropriate behavior and vaccines remained the most important measures. The best practice is to vaccinate all the citizens with the COVID-19 vaccine as quickly as possible. Many countries like Israel, UK, USA have achieved this, and the infection rate is visibly decreasing. In India, COVISHIELD (a live attenuated vaccine prepared by Serum institute of India in collaboration with Oxford Astra Zeneca) and COVAXIN (killed whole-cell virion developed by Bharat Biotech in collaboration with Indian council of medical research) is being given. These vaccines are efficacious and have excellent safety records. ${ }^{12}$ However, the country is presently facing with shortage of vaccines. To roll out the vaccination program, the Sputnik V vaccine has been given EUA and has been shipped to India from Gamelaya, Russia. The production of Sputnik V will start soon by a Hyderabad-based company named Dr. Reddy's pharmaceuticals. Many states in India are working for the global tendering of the vaccine. Undoubtedly, it's a praiseworthy step and will benefit the citizens of India in controlling the COVID pandemic. However, the final outcome out of these processes is yet to be visible on the ground.

COVID-19 vaccination, the largest vaccination drive in India, started on January 16, 2021. Initially, it was available for the HCW's and the frontline workers. ${ }^{13}$ Later on, the vaccination drive was extended on March 1, 2021, and April 1, 2021, for the senior citizens (more than 60 years) and 45-59 years, respectively. ${ }^{14}$ After $1^{\text {st }}$ May 2021, it was extended to the 18-44 years age group citizens. As of May 15 2021, 170 million doses have been administered, and more than 25 lakh doses are being given daily to the citizens. The vaccination in India is done through one single portal-https://portalcowin.gov.in throughout the country.

\section{RESPONSIBILITY OF A NATION TOWARDS HCW}

Presently vaccination seems to be the way ahead. The HCWs are continuously working towards the management of COVID-19 patients. They are the true warriors. During the management of the COVID crisis, many HCWs have lost their lives and lost their family members. During this pandemic, they are involved entirely $24 \times 7$ in the service of the nation. HCWs never stopped, even if fear loomed in their minds regarding their own health and the heath of their family members. Thus, it's the moral responsibility of a nation to take care of their family members, especially spouses, children, and elderly parents. What best could be done for their family members? And the answer is the vaccination with COVID-19 vaccine on a priority basis. There should include a policy guideline for mandatory vaccination of family members of HCWs. Exhaustive work hours, death of patients, relatives, family members, close friends have led to physical burnout and fragile emotional situation filled with anxiety, depression among HCWs. ${ }^{15}$

Recently guideline has been developed by MoHFW regarding the management of COVID-19 cases in rural, peri-urban and tribal areas. The accredited social health activist (ASHA), Anganwadi workers (AWW), and auxiliary nurse cum midwife (ANMs) will be involved in the identification of COVID-19 suspects, testing with rapid antigen test (RAT), isolation of cases, proper management, and referral of cases in need. ${ }^{16}$ When basic infrastructure is deficient in a vast country like India, and when there is a scarcity of adequate personal protective equipment (PPE) kits, putting these front line workers (FLWs) in COVID management might pose a risk to the health of HCWs and their family members. According to the present policy, a person has to register himself/herself on the CoWIN site and take the slot. ${ }^{17,18}$ This is a nice step, but a bit lengthy, time-consuming process, and computer application is a must to get into the system of registration. With a huge number of persons waiting to take a jab, the slots are used to finish off as early after it opens up on the website. Therefore, Govt needs to provide a mechanism of hassle-free vaccination with COVID-19 to the family members of HCWs. Currently, only one state, i.e., Odisha, is situated in the eastern zone of India and has come out with the guideline to vaccinate family members of all HCWs. ${ }^{19}$ This should be followed all over India.

The vaccination of citizens has been adopted by many countries, including India. Though studies are insufficient 
to cite the present scenario, it's evident that the young mass is affected more in the second wave, and it could be due to the initial vaccination drive of senior citizens. Therefore, needless to mention that vaccination is protective. Every section of society is affected, and HCWs are not exempt from the impact of the COVID-19 pandemic. HCWs are affected physically, mentally, and emotionally. The HCWs work for long hours and it's their duty to serve and save the lives of people irrespective of the lockdown, shutdown, or pandemic situation.

Moving beyond HCWs, other frontline functionaries are equally indispensable to tackle COVID-19. Thus, all nations of the world should prioritize the vaccination of family members of HCWs and FLWs on a priority basis. This could be the best possible appraisal of the dedication and devotion of all COVID warriors.

\section{ACKNOWLEDGEMENTS}

The authors would like to thanks all participants who participated in this study.

Funding: No funding sources Conflict of interest: None declared

Ethical approval: Not required

\section{REFERENCES}

1. India COVID: How bad is the second wave? BBC News. Available at: https://www.bbc.com/news/56987209. Accessed on 2021 August 11.

2. COVID-19: What should we do about B.1.617.2? A classic case of decision making under uncertaintyThe BMJ. Available at: https://blogs.bmj.com/bmj/2021/05/17/covid-19what-should-we-do-about-b-1-617-2-a-classic-caseof-decision-making-under-uncertainty/. Accessed on 2021 August 11.

3. Lee LM. Adding justice to the clinical and public health ethics arguments for mandatory seasonal influenza immunization for healthcare workers. J Med Ethics. 2015;41(8):682-6.

4. 270 Doctors Have Died of Covid During Second Wave Of Pandemic: IMA. Available at: https://www.outlookindia.com/website/story/indianews-270-doctors-have-died-of-covid-duringsecond-wave-of-pandemic-ima/383078. Accessed on 2021 August 11.

5. McConnell D. Balancing the duty to treat with the duty to family in the context of the COVID-19 pandemic. J Med Ethics. 2020;46(6):360-3.

6. What We Need to Do to Ensure India's COVID Vaccine Shortage Doesn't Get Worse-The Wire Science. Available at: https://science.thewire.in/health/what-we-need-to-doto-ensure-we-dont-underestimate-indias-vaccineshortage/. Accessed on 2021 August 11.
7. COVID-19 in India: Cases, deaths and oxygen supply. BBC News. 2021. Available at: https://www.bbc.com/news/world-asia-india56891016. Accessed on 2021 August 11.

8. Noronha R. Ground report: How COVID-19 has affected India's rural areas. India Today. Available at: https://www.indiatoday.in/magazine/coverstory/story/20210510-ground-report-how-covid-19has-affected-india-s-rural-areas-1796993-2021-0501. Accessed on 2021 August 11.

9. Why India is seeing higher deaths despite coronavirus variant not being more fatal. Available at: https://theprint.in/opinion/why-india-is-seeinghigher-deaths-despite-coronavirus-variant-not-beingmore-fatal/649788/. Accessed on 2021 August 11.

10. Young need to be more careful, suggests doctor amid raging COVID-19 second wave. Hindustan Times. 2021. Available at: https://www.hindustantimes.com/india-news/youngneed-to-be-more-careful-suggests-doctor-amidraging-covid-19-second-wave101619431570219.html. Accessed on 2021 August 11.

11. Vizheh M, Qorbani M, Arzaghi SM, Muhidin S, Javanmard Z, Esmaeili M. The mental health of healthcare workers in the COVID-19 pandemic: A systematic review. J Diabetes Metab Disord. 2020;26;19(2):1967-78.

12. Ella R, Vadrevu KM, Jogdand H, Prasad S, Reddy S, Sarangi $\mathrm{V}$ et al. Safety and immunogenicity of an inactivated SARS-CoV-2 vaccine, BBV152: a double-blind, randomised, phase 1 trial. Lancet Infect Dis. 2021;21(5):637-46.

13. PM to launch Pan India Rollout of COVID-19 Vaccination drive on January 16. Available at: https://pib.gov.in/pib.gov.in/Pressreleaseshare.aspx? PRID=1688607. Accessed on 2021 August 11.

14. Vaccination above 45 years, all above 45 years of age to get COVID-19 vaccine from April 1, Government of India. Available at: https://www.timesnownews.com/india/article/allabove-45-years-of-age-to-get-covid-19-vaccinefrom-april/736106. Accessed on 2021 August 11.

15. Kim R, Nachman S, Fernandes R, Meyers K, Taylor $\mathrm{M}$, LeBlanc $\mathrm{D}$ et al. Comparison of COVID-19 infections among healthcare workers and nonhealthcare workers. PLOS one. 2020;15(12):e0241956.

16. SOP on COVID-19 Containment and Management in Peri-urban, Rural and Tribal areas. Government of India Ministry of Health and Family Welfare. 2021.

17. CoWIN. Largest Vaccination Drive. Available at: https://www.cowin.gov.in/. Accessed on 2021 August 11.

18. Frequently Asked Questions on Co-WIN. Available at: https://www.cowin.gov.in/faq. Accessed on 2021 August 11.

19. Odisha: Doctors seek priority vaccination for family members. Bhubaneswar News-Times of India. The Times of India. Available at: 
https://timesofindia.indiatimes.com/city/bhubaneswa r/odisha-doctors-seek-priority-vaccination-forfamily-members/articleshow/82632385.cms. Accessed on 2021 August 11.
Cite this article as: Parida SP, Bhatia V, Alekhya G. Revamped vaccination policy in India, need of the hour. Int J Res Med Sci 2021;9:3491-4. 